\title{
EchoGéo
}

$13 \mid 2010$

Afrique, 50 ans d'indépendance : État et territoires

\section{Les murs peints d'Afrique du Sud}

Art ou artifice?

Elisabeth Deliry-Antheaume

\section{(2) OpenEdition}

Journals

Édition électronique

URL : https://journals.openedition.org/echogeo/12023

DOI : 10.4000/echogeo.12023

ISSN : 1963-1197

Éditeur

Pôle de recherche pour l'organisation et la diffusion de l'information géographique (CNRS UMR 8586)

Référence électronique

Elisabeth Deliry-Antheaume, "Les murs peints d'Afrique du Sud », EchoGéo [En ligne], 13 | 2010, mis en ligne le 20 septembre 2010, consulté le 03 août 2021. URL : http://journals.openedition.org/echogeo/ 12023 ; DOI : https://doi.org/10.4000/echogeo.12023

Ce document a été généré automatiquement le 3 août 2021.

EchoGéo est mis à disposition selon les termes de la licence Creative Commons Attribution - Pas d'Utilisation Commerciale - Pas de Modification 4.0 International (CC BY-NC-ND) 


\section{Les murs peints d'Afrique du Sud}

Art ou artifice?

\section{Elisabeth Deliry-Antheaume}

Illustration 1 - Sophiatown

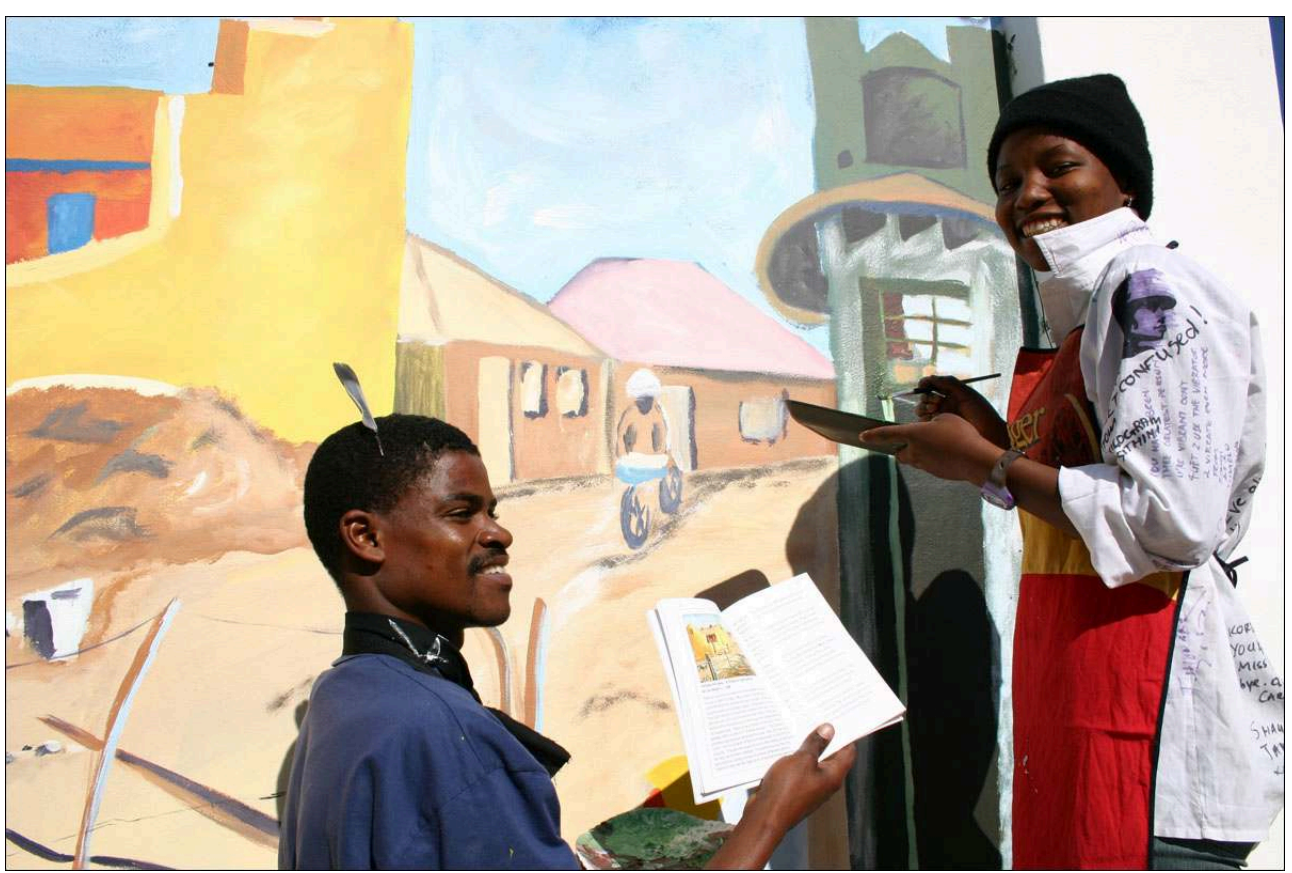

Auteur : Elisabeth Deliry-Antheaume.

En Afrique du Sud, les murs sont consubstantiels à la ville. En raison d'une insécurité récurrente, les murs murent et engendrent des lieux fermés créant des îlots riches et des ghettos pauvres. Mais ces murs murmurent lorsqu'ils sont peints et qu'ils deviennent autant d'éditoriaux éphémères qui se déclinent en de multiples rubriques: histoire, politique, éducation, santé, etc., relayés par de nombreux sponsors. Loin d'être un art sans public, graffitis, murs peints, petits posters ou grandes affiches, juxtaposés 
ou en couches successives, constituent de véritables palimpsestes témoignant de la vitalité urbaine sud-africaine.

2 Depuis 1994, lentement, les voix et les expressions se sont libérées dans tous les domaines, particulièrement dans celui des arts graphiques où la majorité des artistes fut longtemps tenue éloignée des grandes tendances. De témoignages individuels en narrations collectives, la réappropriation de l'espace public devient alors l'objet de négociations et souvent de confrontations.

3 Sans toutefois exclure les anciens préjugés, le retour sur des valeurs communautaires s'accommode d'une ouverture au monde et d'un nouveau regard porté sur autrui. Le débat évoque souvent les modes de représentations, voire l'image ou la culture de l'Autre. Ainsi, la vie quotidienne des quartiers de District Six au Cap ou de Sophiatown à Johannesburg est immortalisée sur les murs. Ces anciens quartiers multiraciaux et multiculturels d'avant le régime de l'apartheid, devenus les symboles d'une culture urbaine perdue, avaient été déguerpis par les autorités de 1955 à 1969 pour se conformer au Group Area Act qui assignait à résidence les populations en fonction de leur appartenance raciale. L'image n'est pas que nostalgie, elle est aussi vision et témoigne d'un futur possible pour l'Afrique du Sud.

4 Les scènes de vie de Sophiatown sont inspirées de l'œuvre de Gérard Soketo. A l'initiative de la Gerard Sekoto Foundation, les jeunes revisitent leur patrimoine culturel, guidés par des artistes reconnus et militants, comme Sam Nhlengethwa, dont la renommée est internationale.

Quels que soient sa place dans la société et le lieu privé ou public d'où il s'exprime, chaque artiste explore territoires et limites, arguant de son passé, mais aussi de l'espérance - compte tenu de l'histoire récente - d'une réunification des espaces et d'une réconciliation entre toutes les communautés. Les peintres empruntent leur vocabulaire au temps et à l'espace et évoquent le processus de transformation à l'œuvre. La route qui sépare Soweto de Johannesburg est une belle métaphore du temps et de la distance qui séparent les communautés. 
Illustration 2 - Soweto

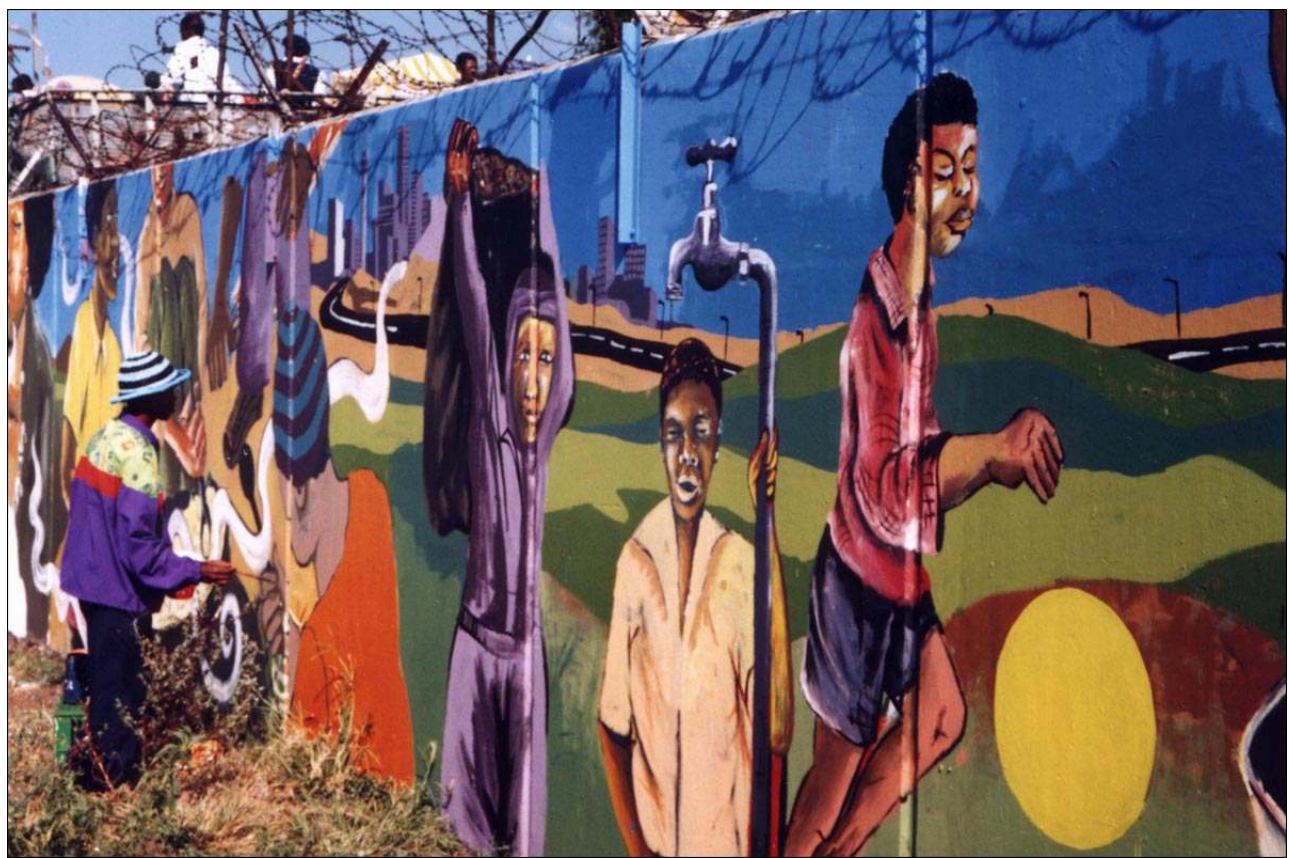

Auteur : Elisabeth Deliry-Antheaume

6 À grands traits de pinceaux et à grands jets de bombes aérosols, les artistes explorent de nouveaux territoires pour l'art... alors que l'eau coule à peine au robinet domestique, le coca-cola s'affiche abondamment.

\section{Illustration 3 - Soweto}

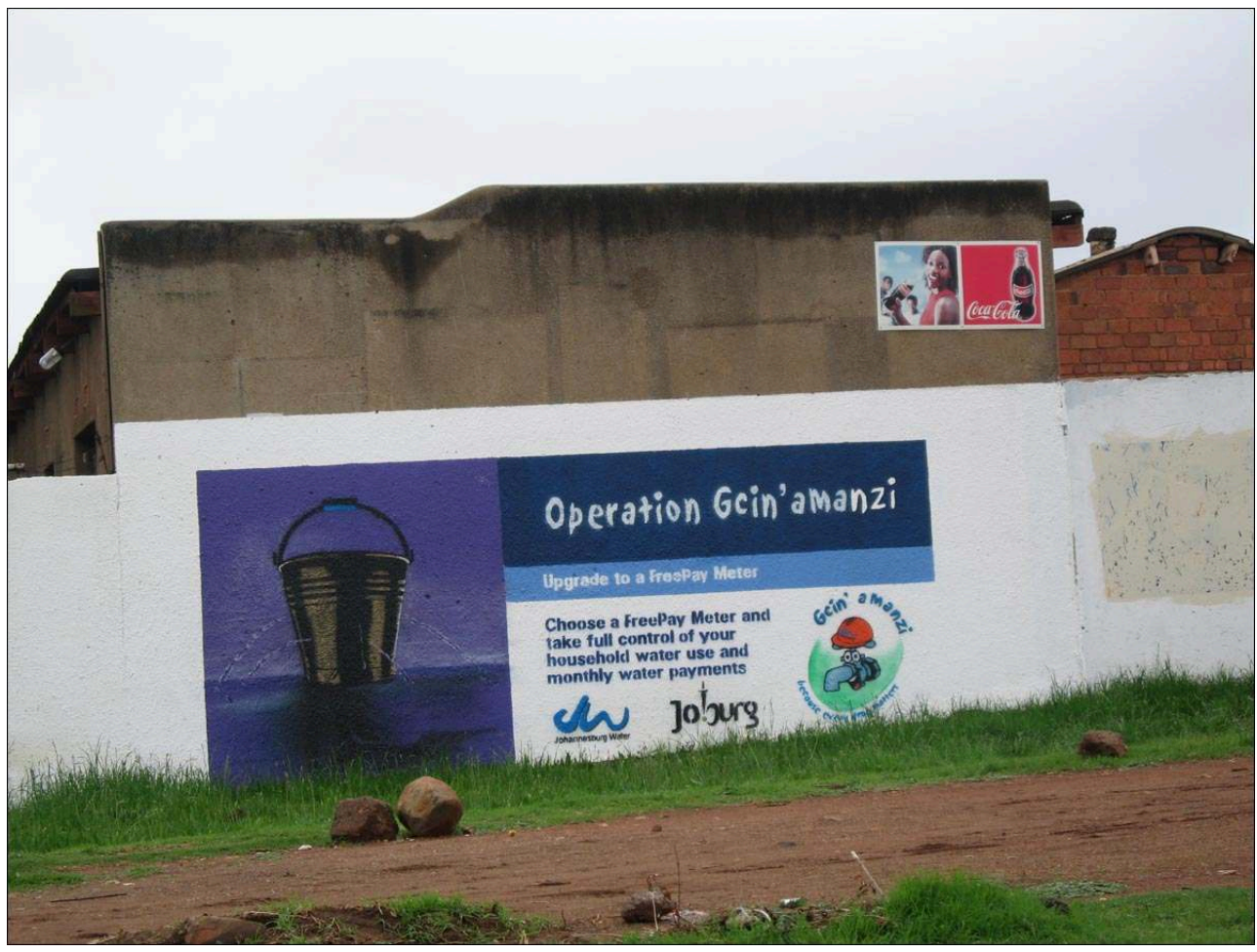

Auteur : Elisabeth Deliry-Antheaume. 
7 Reconnus ou méconnus, les peintres jouent un rôle important dans la construction et l'exposition de ce savoir intime des villes qu'ils habitent et qu'ils rêvent tout à la fois. Le passant est pris à témoin: l'art, mensonge ou artifice, invite à pénétrer la réalité d'aujourd'hui.

Illustration 4 - Capetown

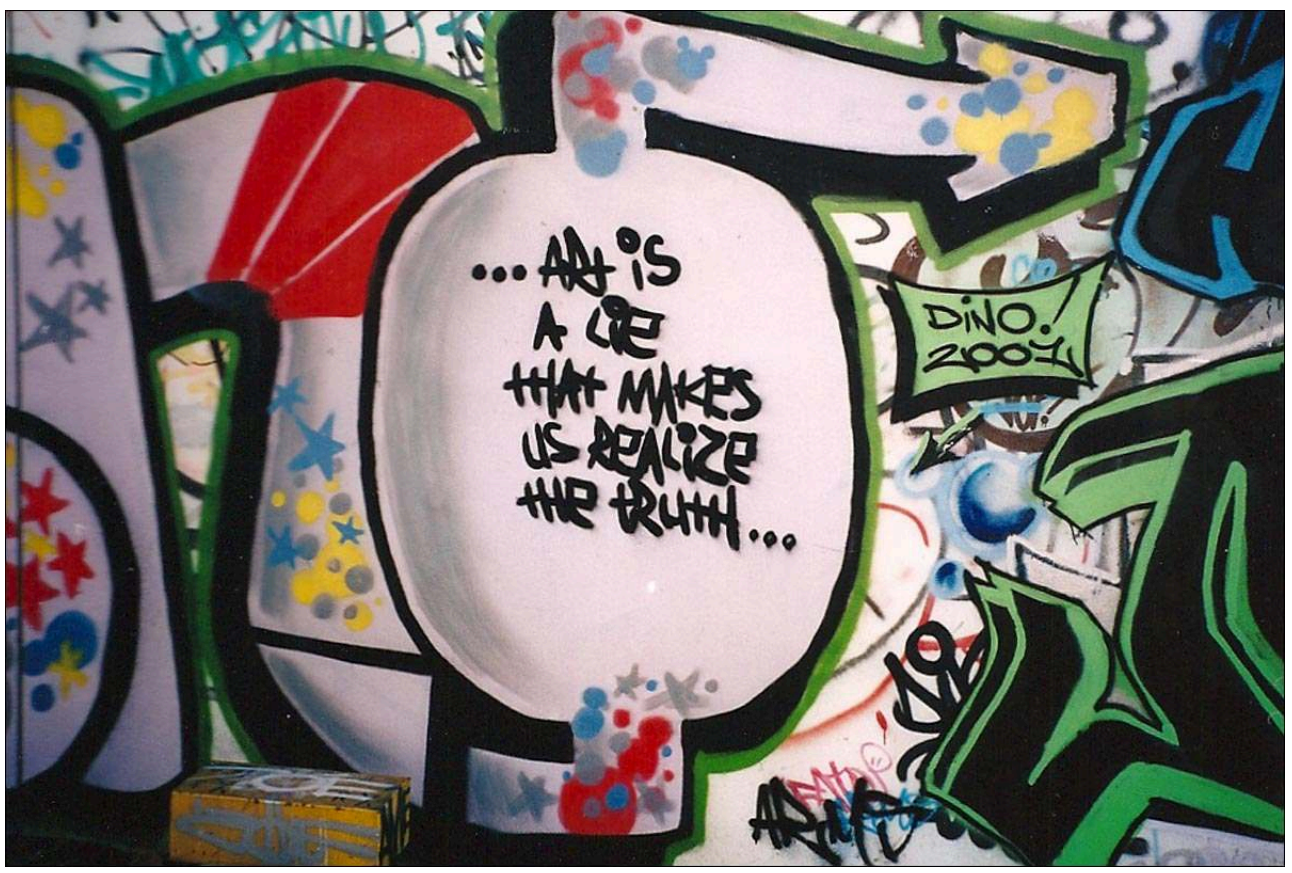

Auteur : Elisabeth Deliry-Antheaume

\section{BIBLIOGRAPHIE}

Deliry-Antheaume E., 2004. Des murs peints contre le sida ; Mural paintings agains the AIDS. La Recherche, $\mathrm{n}^{\circ} 375$, p. 68-75.

Deliry-Antheaume E., 1999. Murs des écoles, école des murs en Afrique du Sud. Les institutions éducatives vues du dehors. Autrepart, ${ }^{\circ} 17$, p. 167-182.

Antheaume B. \& Deliry-Antheaume E., 1999. Cartes d'identité : Les murs peints d'Afrique du Sud. Mappemonde, $n^{\circ}$ 53(1), p. 1-5. http://www.mgm.fr/PUB/Mappemonde/M199/Antheaume.pdf

\section{AUTEUR}

\section{ELISABETH DELIRY-ANTHEAUME}

elisabeth.deliry-antheaume@wanadoo.fr 